\title{
Afetividade e aprendizagem
}

Amparo Caridade*

A vida se apresenta a nós no fim da eternidade, mas e aprendemos nos instantes especiais em que nos demos conta da existência de que estamos inseridos no mundo. Diante de nós esse mundo não cessa de se revelar. Ai cada coisa tem um enigma, um fascínio, uma face a desvendar. Quando nos apercebemos do fenômeno começa a descoberta, o enternecicimento e o prazer crescente de conhecer, sentir, descobrir, pensar e partilhar. Instala-se em nós um desassossego epistemológico, que procede tanto desse cantato com o mundo externo, como de nossa interioridade, lugar em que nos reencontramos e dentro do qual vemos melhor. Basta lembrar que fechamos os olhos quando queremos ver e sentir mais profundamente. Quando observamos e nós entregamos à experiências, a mente desliza numa comunhão com as coisas, com os fatos com o mistério pasta ao desvendamento. Isso supõe um espreguiçamento do espírito, uma interação viva com o universo. "A existência das coisas terá uma feição original em sua percepção pelos olhos do espírito", diz Walter Trinca (1), considerando que uma experiência pessoal profunda pode 
traduzir-se num corpo de conhecimentos, e que uma ciência daí provenience terá o frescor da vida.

O mistério que envolve o mundo, é o próprio objeto da ciência, e é coma observadores participantes desse espetáculo do mundo, que tomamos pane na relação com o objeto de conhecimento. E quando seres inquietos e enternecidos frente ao universo, que conseguiremos passar afetiva e afetivamente esse saber extraído da relação íntima com os fatos e com a vida. É desse enternecimento que procedem nossos gestos como educadores. Um encontro consigo mesmo, uma paixão pelo ser e existir, são necessários, para que se possa falar da necessidade de conhecer quando um bem. É preciso desencadear no aluno a paixão pela descoberta de si e do mundo, e isso só fazemos quando estamos movidos pela mesma paixão. Não podemos prescindir do que somos na arte de iluminar o palco da existência do outro. Nesse contexto a veiculação do saber se da um jorro afetivo-existencial que atinge o aluno em sua pessoa, provocando mudanças importantes, abrindo-lhe ternos caminhos à pulsão de saber.

Suely Rolnik comenta um texto seu "Pensamento, Corpo a Devir Uma Perspectiva Ético/Éstético/Política no Trabalho Acadêmico “, (2) que, o que o professor produz e transmite, tem íntima conexão com o que ela chama de "marcas", não com a conotação de sinal, impressão, que non é familiar, mas como estados que se produzem em nosso corpo a partir de composições que vivemos. são estados disparadores de devir no sujeito. E quanto mais nossa produção é movida pelas marcas, quanto mais ela espelha essa textura ontológica, maior o brilho do que fazemos e mais eterna sua atualidade.

O que o professor não é tanto um saber. Ele ensina a aprender, a criar, o que lhe possibita também ser aprendiz e criador. É como tal, que ele se revela enquanto pensador. A bagagem teórica utilizada não é o único registro que deixamos no aluno. É no "como fazemos", que veiculamos pedaços do que somos e isso repercute em seu desenvolvimento global.

Suely apoiada na visão de Proust e Deleuze, diz que a sua inteligência se segue a isso, vem depois, e que ela só é boa, quando passa a serviço de um nova devir que as "marcas" engendram (3). Como se fosse necessário um acordar existencial, para que a inteligência encontre terreno próprio para sua expansão a pleno desenvolvimento. Conhecemos bem quanto o aluno aprende com sabor, quando lhe possibilitamos o entendimento de si, do outro e do mundo. Uma compreensão que está para além do intelectual, que é veiculada numa metalinguagem, presente na bagagem humana do educador.

Nessa prática pedagógica, a relação aluno/professor é da ordem da cumplicidade, feita de uma crença amorosa na possibilidade de que o aluno tem de desenvolver seu trabalho. para suscitar este aprendiz criador no aluno, o professor tem de estar podendo suscitá-lo em si mesmo, e isso 
acontece na medida em que ele reúne o saber com uma texture ontoló1gica, o que resulta num aprendizado infinito. Quanto mais esse aprendizado está sendo possível ao professor, mais ele consegue autorizá-lo e suscitá-lo no aluno, e também mais prazeroso e gratificante fica seu ofício.

O professor é um profissional cuja bagagem existencial se estampa naquilo que ele faz: ensinar e aprender, a descobrir, a inventar. E o que ele revela ensinando, é se ele é também um aprendiz inventor, se ele descobre no dia a dia, a "beleza de ser um eterno aprendiz". Na cumplicidade amorosa com seu oficio e com seu aluno, o professor usará o teórico conceitual, não como escudo, um esconderijo para sua alma, mas como alicerce de um devir, epifania talvez da plenitude do outro, seu aluno. Ensinando com afeto, o professor gera a possibilidade de emergência do ser afetivo do aprendiz. Diria que a afetividade com que o professor faz sua tarefa, motiva o desassossego afetivo e cognitivo do aluno. Em geral a criança é ímpelida, por exemplo, a voltar-se para o problema de suas origens. Essa é a curiosidade primária, mas que em nada difere da que mantém o pesquisador em seu laboratório. É pulsão de conhecer. É tão epistemológica como outras buscas de saber. A criança quer desvendar enigmas, sobretudo aquele que lhe trouxe à vida. Acuriosidade sexual desperta multo cedo, e está ligada ao nascimento da inteligência. "Insatisfeita, ela pode bloquear a pulsão de saber e entravar o desenvolvirrrento intelectual", (4) mas se for acolhida afetivamente, a criança dará um salto significativo em seu desenvolvimento.

Mas o professor também tem suas carências, insuficiências de seu dever, de seu ser aprendiz, e pode dificultar o aprendiz do aluno, se ele mesmo não se revê, não se revoluciona, não se constrói continuamente como sujeito. No terreno afetivo/sexual há muitas carências informativas e atitudinais em docentes cuja geração foi preconceituosamente privada de uma educação aberta para a vida, para o afeto e sobretudo para a sexualidade. Viver afetivamente a tarefa docente, supõe uma intimidade com o afeto, porventura desenvolvido por nós.

Uma professora cita o exemplo de ter em sala de aula, uma criança em meio pobre as outras crianças burguesas que a rejeitam. Ela passou então a brincar com a menina para aliviar-lhe esse sofrimento. Diria que essa é uma atitude equivocada, que sua tarefa não é brincar neste caso, mas transformar aquele pedaço de sociedade que lhe cabe educar. Ela tem diante de si a fantástica oportunidade de desvendar para as crianças a questão da desigualdade social e sua existência no próprio contexto da sala de aula. E oferece ás crianças a oportunidade de lidarem com a questão e de desenvolverem condutas mais conscientes e humanizadas. Ela tem a oportunidade de mostrar como é injusta aquela rejeição, já que ser pobre não é um desvalor da pessoa, embora a pobreza seja uma anomia, uma doença social. Essa atitude é mais afetiva, mais profissional e mais revolucionária. Sem duvida também mais perigosa sobretudo quando se lida com escolas burguesas. Corremos risco 
sempre que fazemos algo sério. "Viver é muito perigoso" dizia Guimarães Rosa. A tarefa do professor é das mais arriscadas por que ele é um transformador, e isso não interessa aos sistemas autoritários. Não é a toa que ganhamos tão pouco. Com salários tão baixos fica intrigante nossa ousadia de continuar. Algo singular, carismático, move essa profissão. Gostamos do perigo a do mistério que a envolve. Vivemos lia corda bamba da existência onde somos dramaticamente responsabilizados pelo significado do que fazemos. Como se a vida nos colocasse contra a parede. Sem encontrar esse sentido, não nos apreciamos como pessoas.

Temos também responsabilidades com nossa própria felicidade. Essa é uma condição que nos compete unicamente. Ninguém pode sê-to por nós. Precisamos encontrar saída para nossos gemidos existenciais. A sala de aula é também lugar para a aprendizagem disso. não postulo aqui uma pedagogia da felicidadee, não creio nisso. Ela não se ensina. Felicidade se descobre, se constrói, por isso temos compromisso com ela. $\mathrm{O}$ educador comprometido com a própria felicidade, transmite essa possibilidade ao aluno. $\mathrm{O}$ afeto, a ternura, são caminhos possibilitadores do encontro consigo e com o outro, condições básicas de realização humana, motivo de felicidade. É nesse aprendizado descoberta, que se estrutura a marca do afetivo, e ela manterá o sujeito vinculado amorosamente aos outros e a vida. A escola enquanto lugar por excelência do desenvolvimento do indivíduo, há que ternura a missão que lhe cabe de ensinar/revelar a vida. Neste sentido, o professor ensina mais com a atitude, com a vida. Como ele é posto freqüentemente como modelo, como possibilidade identificatória, não pode improvisar-se em sua felicidade. A atitude, o ser, não se improvisam.

Gosto de pensar o afeto como a emoção que torna o outro especial. Algo que é estruturante do sujeito e da relação, algo que o desassossega em seu devir, porque o outro não é mais o mesmo depois que é amado. Ele dispara em sua potencialidade de aprendiz, porque gera-se um acreditar em si, um gostar-se, um reconhecer-se capaz. Talvez o afeto seja a dimensão que mais se aproxima da possibilidade de preenchermos o princípio de insuficiência que é tão esmagador na experiência humana. Estado vivido tanto pelo aluno como pelo professor, uma reciprocidade de carências que é marca humana. Por isso precisamos tanto, dar e receber afeto. Ele nos faz nascer para o outro e o outro para nós. Quando isso acontece, instala-se o desassossego de sermos cada vez mais.

A afetividade nessa relação se dá quando torno particular o aluno, quando o singularizo com pessoa, quando o compreendo em sua busca, quando o alcanço em suas necessidades existenciais e intelectuais. Os textos postos à leitura por exemplo, podem ser disparadores de uma evolução pessoal, de um dever inimaginável. É profundamente gratificante, emocionante mesmo, constatar os saltos qualitativos dados pelo aluno. $\mathrm{O}$ afeto se revela também nessa instrumentalização que o professor faz ao seu crescimento no carinho que ele experiência frente a suas conquistas. 
Cuidar do ser que se desenvolve é a expressão afetiva de maior ressonância para o existir humano. Heidegger diz isso através de uma parábola: Um dia, Cuidado passeando pelo rio, apanhou um pouco de barro e pôs-se a modelá-lo. Ao ver Júpiter, pediu-lhe que soprasse seu espírito sobre a criatura, o que Júpiter prontamente o fez. Mas em seguida inicio-se uma grande disputa entre eles: Júpiter queria a posse da criatura, por ter lhe dado o espírito. Cuidado a queria para si uma vez que a tinha modelado. A Terra também se levantou reclamando-a como parte de si, de seu próprio corpo. Instalada a confusão, eis que aparece Mercúrio, que foi convidado para ser Juiz da situação. Mercúrio então decretou: Já que foi Júpiter que deu espírito a criatura, aterá de volta quando morrer. Como foi a terra que lhe deu a matéria, também a terá de volta com a morte. Mas como foi Cuidado que a plasmou, a terá sob seu cuidado até a morte. Quanto ao nome, será chamado de Homo, que significa feito de humus. Fica a mensagem do sentido que o cuidado adquire na vida do ser humano. Cuidar do aluno, é acompanhá-lo em seu desabrochar pleno: físico, emocional e intelectual. A tarefa educativa requer de nós, o espírito de Júpiter, a matéria prima da natureza, e a habilidade de Cuidado, na construção do ser humano.

Vivemos um tempo de maior embotamento afetivo. A pós-orgia da modernidade nos esvaziou de referencias capazes de ordenar o caos que se instalou sobre tudo na ordem do relacional. Submetemo-nos aos ditames da cultura do efêmero, da velocidade, da superficialidade, que nos põe em defesa de um contato mais profundo com o outro. Gaiarsa queixa-se disso dizendo: "Quanto mais civilizados, mais assépticos, mais distante e mais frios. Só palavras. Pouca mímica. Nenhum contato". (5) $\mathrm{Na}$ verdade somos uma sociedade onde as pessoas não se tocam fisicamente, nem noutras dimensões. A tendência é as palavras ocuparem o lugar da experiência.

O toque é necessário a nossa homeostase física, emocional e existencial. No dizer de Giovanni, "Eu sei que tocar foi, ainda é, e sempre será a verdadeira revolução", e Novalis completa: "Tocamos o céu quando colocamos nossas mãos num corpo humano" (6). Além do sentido estruturante e terapêutico do toque, há uma dimensão de sacralidade, também por ele veiculada, que é disparadora do transcendental na pessoa. Ouso sugerir que ele seja também disparador da inteligência humana, na medida em que representa a acolhida do outgo, fonte de conhecimento a cerca de si mesmo. Conhecendo-se, o sujeito abre-se a descobertas inimagináveis. Como se inteligência encontrasse chão face à disposição afetiva e acolhedora do outro. Às vezes um sinal afetivo por parte do professor, um aperto de mão, um abraço, é resgastador da autoconfiança, da auto-estima, e de abertura para a vida a suas descobertas, por isso: "Precisa-se de ternura natural, desesperadamente", diz J. Salomé. (7) Torna-se porém fundamental, uma clara compreensão do lugar do afeto na relação aluno/professor, para que 
ela não resvale para o terreno equivocado da falsa liberação, onde se passaria ao exercício não de uma relação de pessoa, mas quem sabe até de objeto sexual. Abusos dessa ordem têm ocorrido. É importante que os contatos se estabeleçam na dimensão da relação EU-TU e não do EU-ISSO. (8)

Otávio Paz, comentando estudos sobre a saúde histórica e moral de nossa sociedade, denuncia como nas diversas especialidades, há carência de reflexões sobre o amor, omissão bem característica de nossa época. Diz ele: "O caso da nossa imagem do amor seria uma catástrofe maior que a derrubada de nossos sistemas econômicos e politicos: seria o fim de nossa civilização, ou seja, de nossa maneira de sentir e viver". (9) Mas, embora o amor continue sendo o terra dos poetas e romancistas do Séc. XX, está ferido em seu cerne, ou seja, a noção de pessoa. A idéia do amor ameaça a dissolver, segundo O. Paz, e seus principais inimigos são, a promiscuidade que o transforma em passatempo, e o dinheiro que o converte em servidão. A cura do mundo, a regeneração política, passaria pela ressurreição do amor. "Sob pena de extinção temos de encontrar uma visão do homem a da mulher que nos devolva a consciência da singularidade a da identidade de cada um, uma visão que encase cada ser humano como criatura única, irrepetível e preciosa". ( 10)

Ouso contrapor à inquietação de $\mathrm{O}$. Paz, a esperança de podermos lutar contra o ocaso do amor, se plantarmos sua semente nas crianças a jovens que aprendem conosco, se nutrirmos nele o respeito pelo ser pessoa que somos, se mantivermos nas relações com eles, a chama do afeto que os singulariza como seres especiais. Acima de tudo se os acolhermos carinhosamente em seus desassossegos existenciais, e se soubermos anunciar-lhes a importância que o outro tem em nossa vida, esse outro que se torna para nós como uma segunda pele necessária. Rainer Maria Rilke, encantado pela inscrição do outro em si, termina assim seu poema Retrato interior: "Não tenho necessidade/de te ver aparecer/bastou-me ter nascido,/para te perder um pouco menos".

Deslize, a idéia de afeto para o amor, com uma conseqüência que me parece natural, entendo o afeto como uma emoção particular que segues o cultivo do sentimento mains do amor, que nos vincula enquanto humanidade. Como Bachelard, sonho com um ser, "Esse novo ser é um homem feliz", (11) diz ele. Esse homem nós também o construímos em nossa tarefa de educar. Vemo-lo desabrochar, e feito planta que se cuida, ternuramos a existência. Facilitamos assim a aprendizagem e suas conquistas. Epifania de certo, dense sonho bom do homem sábio e feliz, Emociona-me pensar, que somos nutridores dense sonho, porque,

"Sem o sonho, não há poesia possível

E sem poesia, não há vida suportável". 


\section{REFERÊNCIAS BIBLIOGRÁFICAS}

1. TRINCA, W.: A Eterna Leveza da Experiência. Siciliano, São Paulo, 1994.

2. ROLNIK, S.: In Cadernos da PUC.

$3 . \quad$ Idem.

4. JAGSTAIDT V.: A Sexualidade e a Criança. Ed. Manolc. São Paulo, 1987.

5. MONTAGU. A.: Tocar. O Significado Humano da Pele. Summus Ed., São Paulo, 1988.

$6 . \quad$ Idem.

7. SALOMÉ, J.: Cativando a Ternura. Votes, Petrópolis, 1994.

8. BUBER, M.: A Relação Eu e Tu. Cortez e Moraes, São Paulo, 1979.

9. PAZ, O,: A Dupla Chama: O Amor e o Erotismo. Siciliano, São Paulo. 1992.

10. Idem.

11. BACHELARD, G.: O Direito de Sonhar. DI FEL, São Paulo, 1986. 